\title{
APLICAÇÃO DA LIPASE Candida antarctica B IMOBILIZADA EM PHBV E PU NA CATÁLISE DE REAÇÕES DE SÍNTESE
}

\author{
N. L. D. NYARI ${ }^{1}$, I. A. FERNANDES ${ }^{1}$, JAMILE ZENI ${ }^{1}$, A. M. MOREIRA ${ }^{1}$, D. \\ OLIVEIRA $^{2}$, J. V. OLIVEIRA ${ }^{2}$, E. RIGO $^{3}$
}

\author{
${ }^{1}$ Universidade Regional Integrada do Alto Uruguai e Missões- Departamento de Engenharia \\ de Alimentos \\ ${ }^{2}$ Universidade Federal de Santa Catarina- Departamento de Engenharia Química e Engenharia \\ de Alimentos \\ ${ }^{3}$ Universidade do Estado de Santa Catarina- Departamento de Engenharia de Alimentos \\ E-mail: nadialigianara@ hotmail.com
}

\begin{abstract}
RESUMO: O objetivo deste trabalho foi avaliar a aplicação da lipase imobilizada em PHBV e PU na catálise de reações para síntese enzimática dos ésteres geranil oleato, geranil propionato e oleato de etila. A enzima utilizada nesta pesquisa foi a lipase de Candida antarctica B (Novozymes NZL-102, CAL B), adquirida na forma líquida da empresa Novozymes Latin América Ltda. A enzima CalB foi imobilizada em nanopartículas de poli-hidroxibutirato-co-hidroxivalerato (PHBV) e espuma de poliuretano (PU). A aplicação do imobilizado nas reações de produção de geraniol oleato apresentou 88,0 e $87,7 \%$ de rendimento, para o PHBV e PU, respectivamente. Para a síntese de oleato de etila, a CalB imobilizada em PHBV e PU apresentou 17,4 e 19,3\% de rendimento, respectivamente. Na síntese de geranil propionato ambas as enzimas imobilizadas não apresentaram rendimento. Em termos de aplicação da lipase CalB imobilizada em nanopartículas de PHBV e espuma de poliuretano ambas apresentaram conversão para síntese de geranil oleato e oleato de etila.
\end{abstract}

\section{INTRODUÇÃO}

A aplicação das lipases como biocatalisadores em processos industriais tem ocorrido em indústrias alimentícias, têxtil, de papel; e celulose, detergentes, óleos e gorduras, etc. Assim, esta classe de enzimas vêm conquistando uma faixa crescente do mercado de enzimas industriais com novas aplicações biotecnológicas estabelecidas com sucesso na síntese de biopolímeros e biodiesel, a produção de compostos farmacêuticos enantiopuros, agroquímicos e sabores (flavour) (Dalla Vecchia et al., 2004; Hasan et al., 2006; Kapoor e Gupta, 2012).

De acordo com Castilho (2001) é de suma importância a escolha da enzima "ideal" que será utilizada no processo após a investigação sobre os fatores que influenciam sua aplicação em processos industriais. Esta definição repercute na necessidade de estudos quanto ao uso de lipases principalmente em aplicações industriais de larga escala, devido suas características peculiares, pois são biocatalisadores acessíveis, ou seja, de fácil produção, baixo custo de geração, não requerimento de cofatores, operação em condições brandas de temperatura e $\mathrm{pH}$, minimização de problemas de isomerização, racemização e rearranjo e estabilidade à solventes orgânicos. 
Assim as lipases, fazem parte de um grupo de enzimas onde o interesse comercial tem aumentado, em função da possibilidade de reverter sua forma de atuação em meio orgânico, de tal forma que reações de esterificação e interesterificação possam ser conduzidas. Tais reações são de extrema importância para o desenvolvimento de novas rotas de processo, para obtenção de produtos novos ou conhecidos a custos mais competitivos ampliando, simultaneamente, o potencial de aplicação das enzimas em processos (Castro et al., 2004; Aravindan et al., 2007; Idris e Bukhari, 2012).

Portanto, a imobilização apresenta-se como uma alternativa atraente, possibilitando produzir biocatalisadores mais estáveis e com boa especificidade ao substrato, eliminando assim, algumas restrições do uso das enzimas em processos industriais (Zanin et al., 2004). A escolha de um biocatalisador imobilizado está relacionada com a possibilidade de aplicação, atividade catalítica, viabilidade de operação contínua do processo, maior facilidade de controle e de separação do produto final, além do aumento de estabilidade ao meio reacional, pH e à temperatura, entre outros (Mendes et al., 2011).

Neste contexto, muitos dos ésteres disponíveis são produzidos por sínteses enzimáticas. A produção biotecnológica de ésteres utilizando lipases tem recebido atenção devido às condições de reações brandas (temperatura, $\mathrm{pH}$ e pressão) envolvidas, o elevado grau de pureza alcançado, bem como a aceitação destes produtos na indústria de alimentos (Martínez et al., 2004).

O objetivo deste trabalho foi avaliar a aplicação da lipase de Candida antarctica B imobilizada em nanoparticulas de PHBV e espuma de PU na catálise de reações para síntese enzimática dos ésteres geranil oleato, geranil propionato e oleato de etila.

\section{MATERIAL E MÉTODOS}

\subsection{Metodologia}

A enzima utilizada nesta pesquisa foi a lipase de Candida antarctica B (Novozymes NZL-102, CalB), adquirida na forma líquida da empresa Novozymes Latin América Ltda. A enzima CalB foi imobilizada em nanopartículas de poli-hidroxibutirato-co-hidroxivalerato (PHBV) e espuma de poliuretano (PU).

Poli (hidroxibutirato-co-hidroxivalerato): o polímero poli(hidroxibutirato-cohidroxivalerato) (PHBV) com massa molar $\left(\mathrm{M}_{\mathrm{w}}\right)$ de 196.000 e índice de poli dispersão de 1,85 foi gentilmente cedido pela empresa PHB Industrial S/A. O polímero foi submetido a uma pré-purificação, pela sua dissolução em clorofórmio e posterior precipitação em nheptano para retirada de impurezas.

Poliuretano: Os monômeros comerciais poliol e isocianato, utilizados nesse trabalho foram produzidos com uma formulação específica para colchões e espumas injetadas pela Empresa Flexível Poliuretanos - Mannes. O PU formado com os referidos monômeros resulta no PU do tipo flexível. 


\subsection{Imobilização da CalB utilizando PHBV como suporte}

Precipitação do polímero PHBV para formação de nanopartículas: A precipitação do poli (hidroxibutirato-co-hidroxivalerato) (PHBV) purificado foi realizada utilizando dióxido de carbono supercrítico como antissolvente e diclorometano como solvente orgânico utilizando a técnica de Dispersão da Solução Melhorada por Fluidos Supercríticos (SEDS) para formação das nanopartículas, utilizando a metodologia descrita por Franceschi (2009) e Fernandes (2013). O polímero PHBV foi adicionado a $40 \mathrm{~mL}$ de diclorometano.

Dentre os parâmetros investigados, foram mantidos constante a concentração de PHBV (30 mg.mL-1), pressão da solução orgânica (80 bar), a taxa de fluxo da solução de 1 mL.min-1, taxa de fluxo antissolvente de $40 \mathrm{~mL}$.min-1 e temperatura de $40{ }^{\circ} \mathrm{C}$, com capilar de $100 \mu \mathrm{m}$, com base no trabalho de Franceschi (2009).

Processo de imobilização da CalB utilizando PHBV como suporte: Em tubos de centrífuga de $50 \mathrm{~mL}$, foram adicionados $0,1 \mathrm{~g}$ de nanopartículas de PHBV e $10 \mathrm{~mL}$ de solução enzimática da lipase CalB. Os tubos foram mantidos sob agitação suave de $7 \mathrm{rpm}$ (Silva et al., 2012) em agitador rotatório. Os parâmetros de imobilização, tempo de contato da enzima com as partículas de PHBV e o pH da solução enzimática, foram avaliados, buscando verificar a influência destes parâmetros no processo de imobilização da CalB utilizando PHBV como suporte. O tempo de imobilização foi avaliado em 30, 60, 90, 120 e $150 \mathrm{~min}$, em tampão fosfato de sódio $25 \mathrm{mM}, \mathrm{pH}$ 7, segundo metodologia proposta por Rodrigues et al. (2008).

A avaliação do efeito do $\mathrm{pH}$ na imobilização da enzima foi realizada utilizando-se o melhor tempo de imobilização (120 min) em diferentes tampões, na concentração de $25 \mathrm{mM}$, seguindo a faixa de $\mathrm{pH}$ estipulada para cada solução tampão, ou seja, acetato de sódio para $\mathrm{pH}$ 5; fosfato de sódio para os pHs 6, 7 e 8; tris aminometano para pH 9 e carbonato de sódio para $\mathrm{pH}$ 10. Posteriormente, separou-se o suporte PHBV impregnado da enzima (imobilizado) da solução enzimática (sobrenadante) por filtração a vácuo, realizando-se lavagem com água destilada sob filtro do aparato conectado a bomba a vácuo. Após, o imobilizado foi mantido durante 24 horas em dessecador para equalização do teor de umidade.

\subsection{Imobilização da lipase CalB utilizando poliuretano como suporte}

Polimerização de monômeros: A reação de polimerização do poliuretano foi realizada variando a razão molar dos monômeros poliol:isocianato (5:2, 5:3. 5:4, 5:5 e 3:5 (v/v)), com base no trabalho realizado por Silva et al. (2013) modificado. A reação de polimerização foi conduzida com auxílio de uma seringa graduada pela qual os monômeros foram misturados e, posteriormente, homogeneizados com o auxílio de um bastão de vidro, durante 30 segundos. Após esta etapa ocorreu o estágio de polimerização $(5 \mathrm{~min})$ do poliuretano, expansão da espuma e completa solidificação (Silva et al., 2013, modificado).

Processo de imobilização da CalB utilizando PU como suporte: A imobilização foi conduzida adicionando $10 \%$ do volume de Candida antarctica $\mathrm{B}$ diluída, aos monômeros. Para a imobilização, a enzima foi homogeneizada no monômero poliol e após, ao isocianato, sendo o recipiente mantenedor da mistura envolto em banho de gelo, buscando evitar o aumento excessivo da temperatura devido à reação exotérmica gerada pela mistura dos 
monômeros. Após a etapa de polimerização, o poliuretano contendo a enzima (imobilizado) foi mantido durante 24 horas em dessecador para equalização do teor de umidade.

\subsection{Avaliação da aplicação de lipases na catálise de reações de interesse}

Esterificação enzimática de geraniol e ácido oleico: A esterificação enzimática foi realizada conforme condições otimizadas em trabalho anterior (Paroul et al., 2011), onde misturou-se álcool geraniol e ácido oleico na proporção molar de 3:1. Os substratos foram adicionados em Erlemeyers de $50 \mathrm{~mL}$ com volume médio reacional de $5 \mathrm{~mL}$. Foram adicionados ao meio reacional 10 esferas de peneira molecular. Pesou-se 0,5 g (10\% (p/p)) em relação aos substratos) da enzima CalB imobilizada em PHBV e PU, onde o tempo reacional foi contado a partir da adição da enzima. Todos os experimentos foram realizados em agitador orbital com agitação constante de $160 \mathrm{rpm}$ e temperatura de $40{ }^{\circ} \mathrm{C}$. Após o término do tempo de reação que foi fixado em 6 horas, o biocatalisador foi filtrado com papel filtro. A quantificação da conversão em ésteres foi realizada por titulação com $\mathrm{NaOH} 0,05 \mathrm{M}$ até pH 11. Posteriormente, foi efetuada a determinação do rendimento da síntese de geranil oleato.

Esterificação enzimática de geraniol e ácido propiônico: A esterificação enzimática foi realizada conforme condições otimizadas em trabalho anterior (Paroul et al., 2010), onde misturou-se álcool geraniol e ácido propiônico na proporção molar de 3:1. Os substratos foram adicionados em Erlemeyers de $50 \mathrm{~mL}$ com volume médio reacional de $5 \mathrm{~mL}$. Foram adicionados ao meio reacional 10 esferas de peneira molecular. Pesou-se 0,5 g (10\% (p/p)) em relação aos substratos) da enzima CalB imobilizada em PHBV e PU, onde o tempo reacional foi contado a partir da adição da enzima. Todos os experimentos foram realizados em agitador orbital com agitação constante de $160 \mathrm{rpm}$ e temperatura de $40{ }^{\circ} \mathrm{C}$. Após o término do tempo de reação que foi fixado em 6 horas, o biocatalisador foi filtrado com papel filtro. A quantificação da conversão em ésteres foi realizada por titulação com $\mathrm{NaOH} 0,05 \mathrm{M}$ até pH 9. Posteriormente, foi efetuada a determinação do rendimento da síntese de geranil propionato.

Esterificação enzimática de ácido oleico e etanol: A avaliação da capacidade de reação da CalB imobilizada em PHBV e PU na reação de síntese do oleato de etila foi realizada através da reação do ácido oleico e etanol (razão molar (1:1) descrita por Ferraz et al. (2012) modificado. A reação foi conduzida a $40{ }^{\circ} \mathrm{C}$, durante 40 minutos, em frascos de vidro fechados, mantidos em agitador orbital a $160 \mathrm{rpm}$. Alíquotas de $500 \mu \mathrm{L}$ foram retiradas do meio reacional em triplicata e adicionado cada alíquota $15 \mathrm{~mL}$ de uma solução de acetonaetanol (1:1) (v/v) (Paroul, 2011). Posteriormente, foi efetuada a determinação do rendimento da síntese de oleato de etila.

Determinação do rendimento das reações de síntese: A determinação do rendimento foi realizada segundo Paroul (2011), conforme mostram as Equações 1, 2, 3 e 4:

$$
\begin{aligned}
Q a & =v C \\
A r & =\frac{1 \text { mol acido } m}{M M} \\
M a & =\frac{Q a v t}{v a}
\end{aligned}
$$




$$
R=100-\frac{M a 100}{A r}
$$

Sendo:

$\mathrm{A}_{\mathrm{r}}$ : ácido que reagiu (mol); $\mathrm{C}$ : concentração de $\mathrm{NaOH}\left(\right.$ mol. $\left.\mathrm{L}^{-1}\right) ; \mathrm{m}$ : massa de ácido $(\mathrm{g}) ; \mathrm{M}_{\mathrm{a}}$ : mols de ácido oleico (mol); MM: massa molar (g.mol $\left.{ }^{-1}\right) ; \mathrm{Q}_{\mathrm{a}}$ : quantidade de ácido (mol); R: rendimento de conversão (\%); v: volume gasto de $\mathrm{NaOH}(\mathrm{L}) ; \mathrm{v}_{\mathrm{t}}$ : volume total $(\mathrm{mL}) ; \mathrm{v}_{\mathrm{a}}$ : volume de amostra $(\mathrm{mL})$.

\section{RESULTADOS E DISCUSSÃO}

\subsection{Avaliação da imobilização da CalB em PHBV}

Considerando que a enzima CalB apresenta-se na forma líquida, a imobilização desta em nanopartículas de PHBV através do método de adsorção se torna um alternativa viável. Portanto, o polímero PHBV purificado foi precipitado utilizando a técnica de alta pressão (conforme apresenta o item 2.2), para formação das nanopartículas.

O estudo do tempo de imobilização da lipase Candida antarctica $\mathrm{B}$ diluída em solução tampão fosfato de sódio $25 \mathrm{mM}$, pH 7 em nanopartículas de PHBV indicou o período de contato de $120 \mathrm{~min}$, entre a enzima e o suporte necessário para que houvesse um bom fator de imobilização. Resultados similares foram obtidos por Brigida (2006), onde a atividade hidrolítica da CalB solúvel imobilizada em fibra de coco verde permaneceu inalterada após $120 \mathrm{~min}$ a pH 7.

Levando em consideração que o ponto isoelétrico da lipase CalB é o pH 6, os resultados obtidos neste estudo indicaram uma faixa de $\mathrm{pH}$ ótimo próxima do ponto isoelétrico da enzima (Uppenberg et al., 1994; Rodrigues et al., 2008; Sun et al., 2010; Liu et al., 2011).

\subsection{Avaliação da imobilização da CalB em PU}

A avaliação das condições de imobilização permitiu identificar que na razão 5:3 (v/v) de poliol/isocianato, ocorreu a formação de uma espuma mais flexível com poros uniformes e, portanto, esta foi a proporção empregada na avaliação da imobilização da CalB. A quantidade de enzima previamente diluída em tampão, $10 \%(\mathrm{v} / \mathrm{v})$, foi previamente adicionada ao monômero poliol. Após uma etapa de mistura, fez-se a adição do isocianato, deixando polimerizar por 5 minutos. A espuma formada apresentou uma boa uniformidade na estrutura polimérica, o que indica que ocorreu imobilização da enzima.

\subsection{Avaliação da aplicação da lipase CalB imobilizada na catálise de reações de síntese}

A aplicação da lipase imobilizada em PHBV e PU na catálise de reações para síntese enzimática dos ésteres geranil oleato, geranil propionato e oleato de etila estão apresentados na Tabela 1. 
Tabela 1 - Conversões reacionais obtidas nas reações catalisadas pela CalB imobilizada em PHBV e PU na esterificação de geraniol com ácido oleico e propiônico e do ácido oleico e etanol.

\begin{tabular}{lcc}
\hline & \multicolumn{2}{c}{ Conversão da Lipase CalB } \\
& \multicolumn{2}{c}{ Imobilizada (\%) } \\
\hline PHBV & PU \\
Geranil oleato & 88,0 & 87,7 \\
Geranil propionate & 0 & 0 \\
Oleato de etila & 17,4 & 19,3 \\
\hline
\end{tabular}

A aplicação do imobilizado nas reações de produção de geraniol oleato apresentou 88,0 e $87,7 \%$ de rendimento, respectivamente. Resultado similar foi reportado por Paroul et al. (2011), onde foi utilizada a razão molar geraniol:ácido oleico $3: 1$ (v/v), a $40{ }^{\circ} \mathrm{C}, 160 \mathrm{rpm}$ com $10 \%$ enzima imobilizada, obtendo um rendimento de 93,0 \%. Para ambas as enzimas imobilizadas, a reação com geraniol e ácido propiônico não apresentou conversão. Para a síntese de oleato de etila, a CalB imobilizada em PHBV e PU apresentou 17,4 e 19,3\% de rendimento, respectivamente.

Alguns estudos apresentados na literatura relatam a esterificação enzimática em sistema livre de solvente com diferentes ácidos graxos e alcoóis. Paroul (2011) otimizou a produção de geranil propionato na condição de razão molar 3:1 (geraniol : ácido propiônico) e $10 \%$ de enzima Novozym 435, alcançando uma conversão média de 94,6\% em produto.

\section{CONCLUSÃO}

Em termos de aplicação da lipase CalB imobilizada em nanopartículas de PHBV e espuma de poliuretano ambas apresentaram conversão para síntese de geranil oleato e oleato de etila.

De um modo geral, a lipase CalB imobilizada em nanoparticulas de PHBV e espuma de PU utilizada para a esterificação enzimática conduziram a conversões satisfatórias, indicando que um estudo mais detalhado deve ser realizado, buscando a otimização do processo, para os extratos que apresentam, neste sistema reacional, maior potencial de aplicação como biocatalisador.

\section{REFERÊNCIAS BIBLIOGRÁFICAS}

ARAVINDAN, R.; ANBUMATHI, P.; VIRUTHAGIRI, T. Lipase applications in food industry. Indian Journal of Biotechnology, v. 6, p. 141-158, 2007.

BRIGIDA, A. I. S. Estudo da imobilização de lípase tipo B de Candida antarctica utilizando fibra de casca de coco verde como suporte. Dissertação de Mestrado. Fortaleza-CE, 2006.

CASTILHO, L. R. Development of a dynamic filter for integrated perfusion cultivation and purification of recombinant proteins from mammalian cells. VDI-Verlag, Alemanha, 97, 2001. 
CASTRO, H. F; MENDES, A. A.; SANTOS, J. C. Modificação de óleos e gorduras por biotransformação. Quím. Nova, v. 27, p. 146-156, 2004.

DALLA VECCHIA, R.; NASCIMENTO, M. G.; SOLDI, V. Aplicações sintéticas de lipases imobilizadas em polímeros. Quím. Nova, v. 27, p. 623-630, 2004.

FERNANDES, I. A. Estudo da imobilização de lipases utilizando Poli-hidroxibutirato-cohidroxivalerato (PHBV) e Poliuretano (PU) como suportes. 2013. Tese (Doutorado em Engenharia de Alimentos) - Universidade Regional Integrada do Alto Uruguai e Missões, Erechim.

FERRAZ, L. R.; OLIVEIRA, D. dos S.; SILVA, M. F.; RIGO, E.; DI LUCCIO, M.;OLIVEIRA, J. V.; OLIVEIRA, D.; TREICHEL, H. Production and partial characterization of multifunctional lipases by Sporobolomyces ruberrimus using soybean meal, rice meal and sugarcane bagasse as substrates. Biocatalysis and Agricultural Biotechnology, v. 1, p. 243-252, 2012.

FRANCESCHI, E. Precipitação e encapsulamento de $\beta$ - caroteno em PHBV empregando tecnologia supercrítica. Tese de doutorado. Universidade Federal de Santa Catarina, Florianópolis, SC - Brasil, abril de 2009.

HASAN, F.; SHAH, A. A.; HAMEED, A. Industrial aplications of microbial lipases, Enzyme and Microb. Technol., v. 39, p. 235-251, 2006.

IDRIS, A.; BUKHARI, A. Immobilized Candida antarctica lipase B: Hydration, stripping off and application in ring opening polyester synthesis. Biotechnology Advances, v. 30, p. 550$563,2012$.

KAPOOR, M., GUPTA, M. N. Lipase promiscuity and its biochemical applications. Process Biochemistry, v. 40, p. 1-15, 2012.

LIU, Y.; JIA, S.; WU, Q.; RAN, J.; ZHANG, W.; WU, S. Studies of Fe3O4-chitosan nanoparticles prepared by co-precipitation under the magnetic field for lipase immobilization. Catalysis Communications, v. 12, p. 717-720, 2011.

MARTÍNEZ, M.; BRITO, B.; IMPERIAL, J.; RUIZ-ARGÜESO, T. Characterization of a new internal promoter (P3) for Rhizobium leguminosarum hydrogenase accessory genes hupGHIJ. Microbiology, v. 150 (3), p. 665-675, 2004.

MENDES, A. A.; OliveIRA, P. C.; CASTRO, H. F.; GIORDAN, R. L. C. Aplicação de quitosana como suporte para a imobilização de enzimas de interesse industrial. Quím. Nova, v. 34, p. 831-840, 2011.

PAROUL, N. Síntese enzimática de ésteres aromatizantes a partir de diferentes substratos em sistema livre de solvente orgânico. Tese de Doutorado. Universidade de Caxias do Sul, RS Brasil, 2011.

PAROUL, N.; GRZEGOZESKI, L. P.; CHIARADIA, V.; TREICHEL, H.; CANSIAN, R. L.; OLIVEIRA, J. V.; OLIVEIRA, D. Production of geranyl propionate by enzymatic 
esterification of geraniol and propionic acid in solvent-free system. Journal Chemical Technology Biotechnology, v. 85, p. 1636-1641, 2010.

PAROUL, N.; GRZEGOZESKI, L. P.; CHIARADIA, V.; TREICHEL, H.; CANSIAN, R. L.; OLIVEIRA, J. V.; OLIVEIRA, D. Solvent-free geranyl oleate production by enzymatic esterification. Bioprocess and Biosystems Engineering, v. 34, p. 331-337, 2011.

RODRIGUES, D. S.; CAVALCANTE, G. P.; FERREIRA, A. L. O.; GONÇALVES, L. R. B. Immobilization of Candida antarctica lipase type $\mathrm{b}$ by adsorption on activated carbon. Chem. Biochem. Eng. Q., v. 22, p. 125-133, 2008.

SILVA, J. A.; MACEDO, G. P.; RODRIGUES, D. S.; GIORDANO, R. L. C.; GONÇALVES, L. R. B. Immobilization of Candida antarctica lipase B by covalent attachment on chitosan-based hydrogels using different support activation strategies. Biochemical Engineering Journal, v. 60, p. 16-24, 2012,

SILVA, M. F.; RIGO, D.; MOSSI, V.; DALLAGO, R. M.; HENRICK, P.; KUHN, G. O.; DALLA ROSA, C.; OLIVEIRA, D.; OLIVEIRA, J. V.; TREICHEL, H. Evaluation of enzymatic activity of commercial inulinase from Aspergillus niger immobilized in polyurethane foam. Food and Bioproducts Processing, v. 91, p. 54-59, 2013.

SUN, J.; JIANG, Y.; ZHOU, L.; GAO, J. Immobilization of Candida antarctica lipase B by adsorption in organic medium. New Biotechnology, v. 27, p. 53-58, 2010.

ZANIN, G. M.; MORAES, F. F. Enzimas Imobilizadas. In: SAID, S; PIETRO, R.C.L.R. Enzimas como agentes biotecnológicos. Ribeirão Preto: Legis Summa, p. 35-86, 2004.

UPPENBERG, J.; HANSEN, M. T.; PATKAR, S.; JANS, T. A. The sequence, crystal structure determination and refinement of two crystal forms of lipase B from Candida antarctica. Structure, v. 2, p. 293-308, 1994.

\section{AGRADECIMENTOS}

A URI - Erechim, CAPES, CNPq e FAPERGS, pelo apoio institucional e financeiro para a realização deste estudo. 